\title{
O TRABALHO ANÁLOGO AO DE ESCRAVO COMO VIOLAÇÃO À FUNÇÃO SOCIAL DO CONTRATO DE TRABALHO
}

\author{
SLAVE-LIKE LABOUR AS A VIOLATION OF THE SOCIAL FUNCTION OF WORK'S \\ CONTRACT
}

\author{
Anna Marcella Mendes Garcia* \\ Vanessa Rocha Ferreira**
}

\begin{abstract}
RESUMO: O objetivo deste estudo é, a partir da compreensão da natureza contratual da relação de trabalho, aplicar a ela o arcabouço normativo pertinente, tanto constitucional quanto civilista, em particular a noção de função social, para classificar o trabalho em condições análogas à de escravo como uma violação desta. Trata-se de pesquisa qualitativa, eminentemente bibliográfica, tendo sido utilizado o método hipotético dedutivo para testar a hipótese inicial, de que o trabalho escravo é uma violação à função social do contrato de trabalho, confirmandoa.
\end{abstract}

PALAVRAS-CHAVE: Contrato de trabalho. Dignidade humana. Função social do contrato. Trabalho análogo ao de escravo. Violação.

ABSTRACT: The objective of this study is to, underneath the comprehension of the contractual nature of the labor relation, apply to it the respective normative framework, both constitutional and civil, in particular the notion of social function, to classify the work in conditions analogous to the slave as a violation of it. It is a qualitative research, eminently bibliographical, using the hypothetical deductive method to test the initial hypothesis, that slave labor is a violation of the social function of the labor contract, confirming it.

KEYWORDS: Contract of work. Human dignity. Social role of contract. Slave-like labour. Violation.

\footnotetext{
* Mestranda do Programa de Pós-Graduação em Direito da Universidade Federal do Pará (PPGD/UFPA), com bolsa da Coordenação de Aperfeiçoamento de Pessoal de Nível Superior (CAPES) - Código de financiamento 001. Integrante do Grupo de Pesquisa em Trabalho Decente (CESUPA). Email: marcellamendesgarcia@gmail.com.

** Doutora em Direitos Humanos pela Universidade de Salamanca (Espanha). Mestre em Direitos Fundamentais pela Universidade da Amazônia (UNAMA/PA). Pós-Graduada em Direito Público pela Universidade Cândido Mendes (Ucam/RJ). Especialista em Direito Processual pela Universidade da Amazônia (UNAMA/PA). Professora Universitária. Auditora do Tribunal de Contas do Estado do Pará (TCE-PA). E-mail: vanessarochaf@gmail.com. 


\section{INTRODUÇÃ̃O}

O artigo 421 do Código Civil Brasileiro (CC/02) consolidou o instituto da função social - já presente no art. $5^{\circ}$, inciso XXIII da Constituição da República Federativa do Brasil (CFRB/88), em relação à propriedade —, aplicando-o aos contratos, de maneira a condicionar a liberdade de contratar, pois, a partir desta visão, o contrato não importa somente às partes contratantes, mas também à sociedade, na medida em que nela impacta, direta ou indiretamente.

A função social pode ser entendida, resumidamente, como a relação do contrato e dos contratantes com a sociedade, cuja principal consequência, em caso de inobservância, é a decretação de invalidade do negócio jurídico celebrado.

Os contratos, de modo geral, tiveram, então, sua validade condicionada ao cumprimento da função social, isto é, se forem simulados, fraudulentos ou, de alguma forma, causarem danos a terceiros, por exemplo, não serão juridicamente válidos, ainda que presentes os demais requisitos legais.

Compreendendo o contrato de trabalho a partir de sua natureza contratual, aplicar-seá a ele o instituto da função social para, dentre outros fins, criar um mecanismo para impor limites a exploração do trabalhador, sob pena deste contrato ser considerado inválido.

O trabalho, enquanto exercício de um ofício ou profissão, possui papel central na vida do ser humano. É por meio dele que o indivíduo se auto-afirma, expressa sua personalidade e se posiciona na sociedade, além, obviamente, de garantir sua subsistência. Dada sua centralidade, o trabalho não poder ser considerado tão somente como meio de acumulação de capital, devendo, também, ser analisado sob um aspecto social.

O trabalho análogo ao de escravo, cuja exploração é tipificada como crime no artigo 149 do Código Penal Brasileiro (CPB/40), com redação dada pela Lei no 10.803, de 11 de dezembro de 2003, dispõe sobre os modos de execução do ilícito, quais sejam trabalho forçado, jornada exaustiva, condições degradantes e restrição da locomoção do trabalhador. Trata-se de superexploração do trabalhador que constitui grave violação à organização do trabalho e à dignidade e liberdade humanas. Neste artigo, com fundamento na doutrina pertinente, pretendemos classificá-lo, também, como uma ofensa à função social do contrato de trabalho.

Rev. de de Direitos Fundamentais Nas Relações Do Trabalho, Sociais E Empresariais | e-ISSN: 2525-9903 | Goiânia| v. 5 | n. 1 | p. 1-17| Jan/Jun. 2019 
Trata-se de estudo teórico-normativo que, partindo da premissa de que a relação trabalhista é uma modalidade de contrato e que à ela se aplica o instituto da função social, busca testar a hipótese de que a redução do trabalhador à condição análoga à de escravo constitui uma violação à função social do contrato de trabalho.

O trabalho dividir-se-á em quatro seções principais, sendo esta introdução a primeira; a segunda, conceitual, para tratar do princípio da função social do contrato de trabalho, abordando sua previsão constitucional, origem e natureza jurídica, cujo referencial adotado será Farias e Rosenvald; a terceira, igualmente teórica, no intuito de apresentar o conceito brasileiro de trabalho análogo ao de escravo, sua previsão legal, incluindo os modos de execução desta modalidade de trabalho, bem como os bens jurídicos tutelados pelo tipo penal, sendo Brito Filho e Mesquita os principais referenciais teóricos a serem utilizados; e a quarta, para relacionar o trabalho escravo com a função social do trabalho, confirmando a hipótese ventilada.

\section{O PRINCÍPIO DA FUNÇÃO SOCIAL DO CONTRATO DE TRABALHO NO ORDENAMENTO JURÍDICO BRASILEIRO}

Dentro do arcabouço axiológico do Código Civil Brasileiro estão princípios que buscam compatibilizar valores éticos com a técnica jurídica, como a eticidade e a solidariedade, que darão substância aos atos jurídicos nele tutelados, dentre os quais se encontram os contratos.

Estes, via de regra, possuem diversas funções, como por exemplo, a econômica, quando se destina à circulação de riqueza; a de custódia, quando visa a guarda e conservação de bens alheios; e a função social, sobre a qual nos voltaremos mais atentamente neste estudo.

O instituto da função social foi consagrado no direito brasileiro pelo art. $5^{\circ}$, inciso XXIII da Constituição Federal, o qual dispõe, sucintamente, que a propriedade deverá atender à sua função social. Posteriormente, o Código Civil de 2002 também normatizou o instituto, em uma cláusula geral, desta vez, aplicando-o aos contratos, indistintamente, todavia, sem

Rev. de de Direitos Fundamentais Nas Relações Do Trabalho, Sociais E Empresariais | e-ISSN: 2525-9903 | Goiânia| v. 5 | n. 1 | p. 1-17| Jan/Jun. 2019 
definir o que seria tal função, apenas indicando que ela seria uma das limitações à liberdade de contratar.

O surgimento e a consolidação da função social em diversos ramos do direito advém da ideia de solidariedade, prevista como um dos objetivos fundamentais da República Federativa do Brasil, no art. $3^{\circ}$, inciso I, da CRFB/88, pois decorre da noção de que, mesmo entre particulares, os atos jurídicos devem ser pensados, também, de maneira coletiva, isto é, os seus impactos devem ser analisados não somente entre as partes contratantes, mas, também, em relação aos seus reflexos para a sociedade. Nesse sentido, Santos (2013, p. 4781) destaca que:

$\mathrm{Na}$ perspectiva constitucional-civil, portanto, impõe-se atribuir dignidade ao homem contratante sem desprezar o comportamento contratual solidário, de sorte que a tutela não fique reduzida só aos interesses do credor, mas também aos do devedor. $\mathrm{O}$ valor jurídico maior a ser tutelado no novo sistema é o equilíbrio, conforme a atual noção de justiça contratual. A função social do contrato, segundo essa perspectiva, encontra fundamento na Constituição, ora associada à cláusula geral de solidariedade ora ligada à quebra do individualismo e em vista da igualdade substancial. A igualdade material não permite tratamento jurídico muito desigual entre os contratantes.

Assim, percebe-se que a função social, portanto, decorre de uma tendência à socialização de todas as relações, que passam a ser vistas não só individualmente, mas, também, em seus aspectos e impactos econômicos, éticos e sociais.

Trata-se de uma espécie de "conjugação entre os princípios da liberdade e da solidariedade" (FARIAS e ROSENVALD, 2015, p. 184), decorrente de uma tendência de funcionalização que envolve todo o direito, na busca por sua constitucionalização, humanização e eticidade.

Pode ser compreendida, ainda, como um mecanismo de garantia de eficácia dos direitos fundamentais nas relações privadas, tanto em sua dimensão objetiva, em que a função social é reconhecida como norte de interpretação do ordenamento jurídico laboral; quanto na subjetiva, na qual se materializa em direitos subjetivos, passíveis, inclusive, de judicialização, como a garantia ao trabalho decente, intrinsecamente vinculado à dignidade da pessoa humana (FERREIRA, 2016, p. 99-102). 


\section{O TRABALHO ANÁLOGO AO DE ESCRAVO COMO VIOLAÇÃO À FUNÇÃO SOCIAL DO CONTRATO DE TRABALHO}

Não há no ordenamento jurídico vigente uma definição expressa do que consistiria a função social dos contratos, entabulada no art. 421 do $\mathrm{CC} / 02$ - tal qual ocorreu com a propriedade rural, cujos elementos caracterizadores de sua função social estão discriminados no rol do art. 186 da CRFB -, papel este que coube, então, à doutrina.

Para Farias e Rosenvald (2015, p. 184), a função social dos contratos pode ser compreendida da seguinte maneira:

Para além da intrínseca função da circulação de riquezas, o papel das relações negociais consiste em instrumentalizar o contrato em prol de exigências maiores do ordenamento jurídico, tais como a justiça, a segurança, o valor social da livre-iniciativa, o bem comum e o princípio da dignidade da pessoa humana. O epicentro do contrato se desloca do poder jurígeno da vontade e do trânsito de titularidades, para um concerto entre o interesse patrimonial inerente à circulação de riquezas e o interesse social, que lateralmente àquele se projeta.

Os supracitados autores sustentam que não se trata de uma restrição à liberdade de contratar, que ainda permanece plena, e sim de uma legitimação da mesma, que passa por uma espécie de "controle de merecimento" constitucional a quando da análise do cumprimento da função social (FARIAS e ROSENVALD, 2015, p. 185).

Verifica-se, deste modo, que, na contemporaneidade, os contratos, ainda que particulares, são tratados como fatos sociais que não estão restritos às partes anuentes e, como tais, devem atender não somente aos interesses dos contratantes, mas, também, aos interesses sociais da coletividade, conciliando-os.

Em se tratando especificamente do contrato de trabalho, este, em decorrência de sua natureza contratual, de igual modo, deve ser viabilizado de modo a cumprir a sua função social, o que implica na reinterpretação da relação trabalhista, pautando-a de mecanismos protetivos para viabilizar o estrito respeito aos direitos e garantias fundamentais, bem como o respeito à dignidade do trabalhador.

O contrato individual de trabalho pode ser compreendido como uma espécie de contrato típico, previsto no art. 442, da Consolidação das Leis do Trabalho (CLT); que possui as seguintes características: é consensual, pois pautado na autonomia da vontade das partes, ainda que o acordo seja tácito; é não formal, pois não exige forma específica para que seja

Rev. de de Direitos Fundamentais Nas Relações Do Trabalho, Sociais E Empresariais | e-ISSN: 2525-9903 | Goiânia | v. 5 | n. 1 | p. 1-17| Jan/Jun. 2019 
considerado válido; é bilateral ou sinalagmático, tendo em vista a existência de deveres de ambas as partes; é oneroso, ou seja, exige uma retribuição/contraprestação monetária pelo serviço prestado, sendo esta característica, inclusive, um dos requisitos para que se configure a relação de emprego; é pré-estimado, pois há previsibilidade das prestações a serem cumpridas por ambas as partes; e, por fim, é personalíssimo, pois deve ser executado pela pessoa diretamente contratado, característica também exigida para a configuração da relação de emprego.

Coadunando com esta compreensão, Martins (2011, p. 90) sustenta que o contrato de trabalho é uma modalidade de negócio jurídico voltada a entabular as condições de trabalho, representando, assim, um acordo de vontades decorrente da autonomia privadas das partes. $\mathrm{O}$ objeto deste tipo específico de contrato é, portanto, a prestação subordinada, pessoal, nãoeventual e onerosa de serviços, nos moldes dos arts. 442 c/c $2^{\circ}$ e $3^{\circ}$ da CLT.

Todavia, a autonomia privada no contrato de trabalho é restringida por diversos limites impostos pelo ordenamento jurídico nacional e internacional, dentre os quais está destaca-se a função social do contrato de trabalho. Não é possível, assim, que um contrato de trabalho estipule uma jornada de trabalho superior à máxima prevista em lei, que pactue a prática de atividade ilegal, etc.

Martinez (2018, p. 82), abordando a relação entre o Direito do Trabalho e o Direito Civil, pauta-se na natureza contratual da relação de trabalho para afirmar que:

O direito civil é a base fundamental do direito do trabalho. Enfim, aplica-se aos contratos individuais e coletivos de trabalho o integral conteúdo da parte geral da legislação civil, com mínimas alterações decorrentes das vicissitudes do ramo laboral.

Sendo assim, o contrato de trabalho atrai, portanto, todo o arcabouço normativo civil atinente à teoria dos contratos, inclusive, no que tange à necessidade de observância da função social. A utilidade econômica do contrato de trabalho, visada tanto pelo empregador quanto pelo empregado, fica, portanto, condicionada às determinações éticas impostas pelo ordenamento jurídico na forma da função social.

\section{TRABALHO ANÁLOGO AO DE ESCRAVO}

Rev. de de Direitos Fundamentais Nas Relações Do Trabalho, Sociais E Empresariais | e-ISSN: 2525-9903 | Goiânia| v. 5 | n. 1 | p. 1-17| Jan/Jun. 2019 
O conceito de trabalho análogo ao de escravo, no Brasil, está previsto no art. 149 do Código Penal, e consiste, basicamente, na descrição dos modos de execução do crime, que são: trabalhos forçados, jornada exaustiva, condições degradantes e servidão por dívida; bem como as modalidades equiparadas, que são: a retenção do trabalhador no local de trabalho pelo cerceamento do uso de transporte, por vigilância ostensiva e/ou pela retenção de documentos, todas elencadas no $\S 1^{\circ}$.

Importante desde logo ressaltar que, tecnicamente, de acordo com o citado diploma legal, a terminologia correta a ser utilizada é trabalho análogo ao de escravo, e não trabalho escravo propriamente dito, pois a escravidão é um conceito jurídico inexistente no Brasil na atualidade, pois abolida desde 13 de maio de 1888 , com a promulgação da Lei $n^{\circ} 3.353$, conhecida como Lei Áurea.

O trabalho análogo ao de escravo pode ser entendido, então, como aquele cujo exercício se dá em condições semelhantes às da escravidão, contudo, a ela não se equivale, pois é inaceitável jurídica e moralmente que, na atualidade, um ser humano seja proprietário de outro e possa dele dispor irrestritamente.

A escravidão do período colonial brasileiro, permitida legalmente à época, considerava o indivíduo escravizado como um bem e, por conta disto, seu proprietário poderia dele dispor tal qual fazia com quaisquer de seus outros bens, o que implica tanto em torná-lo como objeto de transações comerciais (trocas e venda), quanto nas mais diversas violações à sua integridade física e psicológica. Verifica-se, assim, que por mais degradantes que sejam as condições de trabalho, não há, atualmente, como uma pessoa ser considerada escrava de outra, isto é, de ser considerada uma coisa passível de propriedade alheia.

Desta feita, ao utilizarmos neste estudo a expressão trabalho escravo, coadunamos com autores como Brito Filho, que dela se valem como "forma reduzida da expressão mais ampla e utilizada pela lei" (BRITO FILHO, 2017, p. 40), tanto pela força que carrega, quanto como recurso para facilitar a leitura.

Rev. de de Direitos Fundamentais Nas Relações Do Trabalho, Sociais E Empresariais | e-ISSN: 2525-9903 | Goiânia | v. 5 | n. 1 | p. 1-17| Jan/Jun. 2019 
Conforme dito acima, o conceito legal de trabalho escravo, no Brasil, se resume aos modos de execução dispostos no art. 149 do Código Penal - sem, sequer, esclarecer alguns deles - , de modo que coube à doutrina aprofundar sua definição.

Brito Filho e Albuquerque, por exemplo, definem trabalho escravo como antítese do trabalho decente, e que se perfaz no exercício laboral sem que haja salvaguarda dos direitos fundamentais do trabalhador. Os autores preleciona que:

[...] podemos definir trabalho em condições análogas à de escravo, ou trabalho escravo, como o trabalho prestado por pessoa física em condições que importem na instrumentalização do trabalhador, violando sua dignidade e sua liberdade pessoal, e que possam ser enquadradas em ao menos um dos modos de execução previstos no artigo 149 do Código Penal Brasileiro: trabalho forçado, em jornada exaustiva, em condições degradantes, com restrição de locomoção por dívida contraída, ou com retenção do trabalhador no local de trabalho por meio de vigilância ostensiva, cerceamento dos meios de transporte ou porque o tomador dos serviços se apodera de documentos ou objetos pessoais do prestador dos serviços. (BRITO FILHO; ALBUQUERQUE, 2017, p. 71)

Chaves e Hannemann (2017, p. 282) asseveram que o trabalho em condições análogas à de escravo possui estreita ligação com a submissão extrema de uma pessoa em relação à outra (trabalhador-empregador), constituindo uma relação de sujeição da vítima, explorada, para com seu opressor, explorador, sendo que esta submissão extraordinária atinge o status libertati do indivíduo.

Quando tratam o trabalho escravo como uma ofensa ao status libertati do indivíduo, as autoras ultrapassam o entendimento de que o ilícito só restaria caracterizado quando houvesse restrição à liberdade de locomoção — que é apenas um dos modos de execução do crime em comento - , e incluem a liberdade de autodeterminação do indivíduo como um dos bens jurídicos tutelados pelo tipo penal.

A liberdade de autodeterminação pode ser entendida como o conjunto de liberdades do indivíduo que lhe permitem perseguir seu projeto de vida. Dentre elas está a decisão livre, consciente e autônoma acerca do trabalho que deseja exercer e em quais condições isto se dará. Uma sujeição extrema, como ocorre no trabalho em condições análogas à de escravo, impossibilita o trabalhador de exercer este direito plenamente.

Rev. de de Direitos Fundamentais Nas Relações Do Trabalho, Sociais E Empresariais | e-ISSN: 2525-9903 | Goiânia| v. 5 | n. 1 | p. 1-17| Jan/Jun. 2019 


\section{O TRABALHO ANÁLOGO AO DE ESCRAVO COMO VIOLAÇÃO À FUNÇÃO SOCIAL DO CONTRATO DE TRABALHO}

O trabalho em condições análogas à de escravo, portanto, pode ser entendido como aquele que não respeita as garantias mínimas do trabalhador e que, manifestado em um ou mais modos de execução previstos expressamente no tipo penal, atingem-no tanto em sua autodeterminação quanto em sua dignidade.

Desta conceituação pode-se depreender que o tipo penal buscou resguardar não somente a liberdade de locomoção do indivíduo, como inicialmente foi defendido, mas a liberdade em sentido lato, compreendida enquanto autodeterminação individual, e também, quiçá principalmente, sua dignidade.

Brito Filho, por exemplo, defende que o principal bem jurídico tutelado pelo diploma legal em comento é a dignidade, tendo em vista que alguns dos modos de execução não apresentam violação à liberdade, e sim a um "conjunto mínimo de direitos que a Organização Internacional do Trabalho convencionou denominar trabalho decente, e que são os Direitos Humanos específicos dos trabalhadores" (BRITO FILHO, 2006, p. 126), cujo berço é a Declaração sobre os Princípios e Direitos Fundamentais no Trabalho, da Organização Internacional do Trabalho (OIT), de 1998, e dentre os quais estão: a própria existência de trabalho, liberdade, igualdade, condições justas, preservação da saúde e segurança no ambiente laboral, proibição do trabalho infantil em todas as suas formas, liberdade sindical e proteção contra os riscos sociais.

No mesmo sentido, Neves (2012, p. 59), ao abordar o trabalho análogo ao de escravo, afirma que "[N]ão se trata de valores morais, éticos, religiosos, ideológicos ou culturais, mas sim do valor supremo do ser humano, a sua dignidade".

Em que pese a agora quase inexpressiva divergência doutrinária e jurisprudencial acerca do bem jurídico tutelado pelo art. 149 do Código Penal, verifica-se que o trabalho escravo ofende essencialmente a dignidade da pessoa humana, uma dos pilares do Estado Democrático de Direito, justificando, inclusive, a tutela por parte do Direito Penal, que é, ou deve ser, a ultima ratio.

Quanto aos já citados modos típicos de execução do crime de trabalho escravo, trazidos taxativamente pela nova redação do art. 149 do Código Penal, de acordo com a Lei ${ }^{\circ}$ 10.803, de 11 de dezembro de 2003, temos: i) trabalho forçado; ii) jornada exaustiva; iii)

Rev. de de Direitos Fundamentais Nas Relações Do Trabalho, Sociais E Empresariais | e-ISSN: 2525-9903 | Goiânia | v. 5 | n. 1 | p. 1-17| Jan/Jun. 2019 
condições degradantes de labor e; iv) restrição da locomoção do trabalhador em razão de dívida contraída com o empregador ou preposto.

O primeiro dos modos de execução elencados no dispositivo legal, o trabalho forçado ou obrigatório, pode ser entendido, nos moldes do art. $1^{\circ}$ da Convenção n. 29 da Organização Internacional do Trabalho (OIT) como "todo trabalho ou serviço exigido de um indivíduo sob ameaça de qualquer penalidade e para o qual ele não se ofereceu de espontânea vontade", salvo algumas exceções, como o serviço militar obrigatório, previstas expressamente no art. $2^{\circ}$ do citado diploma internacional (BRASIL, 1957, online).

Nesse sentido, Ferreira (2017, p. 173) defende que a realidade na qual o trabalhador está inserido é importante para a caracterização dessa forma de trabalho. "Se esta pessoa sofrer coação psicológica, moral e física para que dê seguimento à prestação do serviço, tendo assim, violado o seu direito à liberdade de locomoção, não há dúvidas de que se estará diante de caso de trabalho em condição análoga a de escravo".

As jornadas exaustivas, por seu turno, são caracterizadas quando há prejuízo à saúde física ou mental do trabalhador em decorrência da duração da jornada de trabalho, seja pelo tempo que se prolonga, ou pela excessiva intensidade exigida na atividade, de modo a estafar o trabalhador (CHAVES E HANNEMANN, 2017, p. 288).

As condições degradantes de labor, apesar de serem um conceito jurídico indeterminado, doutrinariamente são compreendidas a partir da noção de dignidade humana, sendo assim consideradas todas aquelas que afetam o indivíduo nesta esfera de sua personalidade, tratando-lhe como coisa (CARVALHO apud MESQUITA, 2016, p. 62).

Por fim, a restrição de locomoção em razão de dívida, mais conhecida como servidão por dívida, muito comum quando há aliciamento de trabalhadores, consiste no endividamento do trabalhador, provocado pelo empregador ou preposto, muitas vezes na compra de itens essenciais como alimentação e vestuário, no intuito de mantê-lo no local de trabalho enquanto a dívida não for quitada.

Há, ainda, as modalidades equiparadas, que são a manutenção de vigilância ostensiva, a retenção de documentos e/ou objetos pessoais e a não disponibilização de transporte. Nota-se a presença de um especial fim de agir em todas elas, que consiste no intuito de reter o 
trabalhador no local de trabalho, razão pela qual são tratadas como modos de execução equiparados ao crime de redução do trabalhador à condição análoga à de escravo.

Chaves e Koury exemplificam didaticamente situações que podem ser caracterizadas como trabalho análogo ao de escravo:

A escravidão contemporânea será atestada sempre que o trabalhador for submetido a jornadas de trabalho acima das estipuladas em lei, sem qualquer percepção de adicional por tempo excedente, ou a trabalhar à exaustão; quando ficar exposto a doenças endêmicas ou moléstias e contágios, bem como sofrer maus-tratos físicos e punição severa; quando não puder gozar de descanso semanal remunerado, horas vagas e lazer; quando não lhe for disponibilizada assistência médica e hospitalar; quando tiver seus documentos pessoais apreendidos ou retidos ou, até mesmo, quando houver o próprio cerceamento do direito de ir e vir; quando não lhe for permitido usufruir de condições dignas de higiene, moradia, saneamento, houver ausência de água potável e de alimentação apropriada, ou mesmo quando estiver sujeito à desnutrição. Ressalta-se que as situações acima descritas não são concorrentes entre si, bastando para a caracterização do crime a ocorrência de qualquer uma delas. (CHAVES e KOURY, 2017, p. 230-231)

Como se vê, inúmeras são as situações que podem caracterizar o ilícito de trabalho análogo ao de escravo, todas envolvendo, em maior ou menor grau, ofensas à dignidade do trabalhador enquanto pessoa humana e/ou à sua liberdade de autodeterminação.

\section{TRABALHO ESCRAVO ENQUANTO VIOLAÇÃO À FUNÇÃo SOCIAL DO CONTRATO DE TRABALHO}

Caracterizado o trabalho análogo ao de escravo e compreendida a aplicação da função social ao contrato de trabalho, parte-se para a discussão da hipótese de pesquisa, que é a consideração do trabalho análogo ao de escravo como uma das formas de violação a este instituto.

Em uma interpretação analógica, partindo do rol previsto no art. 186 da CRFB/88, permite compreender a função social do contrato de trabalho em termos similares aos da propriedade rural, guardadas as devidas ressalvas, obviamente, se cumpridos os requisitos de: aproveitamento racional e adequado; utilização adequada dos recursos naturais disponíveis e

Rev. de de Direitos Fundamentais Nas Relações Do Trabalho, Sociais E Empresariais | e-ISSN: 2525-9903 | Goiânia | v. 5 | n. 1 | p. 1-17| Jan/Jun. 2019 
preservação do meio ambiente; observância das disposições que regulam as relações de trabalho; exploração que favoreça o bem-estar dos proprietários e dos trabalhadores.

O aproveitamento racional e adequado, se aplicado ao contrato de trabalho, pode ser vislumbrado como a utilização da mão de obra dentro dos ditames legais, em consonância com os direitos e garantias fundamentais dos trabalhadores ou, resumidamente, no trabalho decente. O trabalho escravo é, sinteticamente, conforme exposto anteriormente, a antítese do trabalho decente, pois se perfaz na instrumentalização do trabalhador, mediante práticas que violam sua dignidade e sua liberdade pessoal (BRITO FILHO; ALBUQUERQUE, 2017, p. 71), o que pode ser compreendido, também, como uma utilização inadequada e irracional da força de trabalho alheia.

Quanto ao segundo requisito, a presença do trabalho escravo pode ser entendida como uma espécie de poluição labor-ambiental, uma vez que o meio ambiente do trabalho é considerado uma das dimensões do meio ambiente. Isto porque o conceito de poluição versa, essencialmente, sobre o desequilíbrio intolerável do meio ambiente e, sendo o ser humano parte integrante deste, sua exploração para além dos limites legais e morais dentro da relação de trabalho implica na degradação de um dos componentes, o humano (MARANHÃO, 2017, p. 255).

A observância das disposições que regulam as relações de trabalho é um dos requisitos mais afetados na ocorrência de trabalho escravo, pois este ilícito viola frontalmente inúmeros dispositivos da CRFB/88 e da CLT, tais como, a depender do caso concreto, os que versam sobre jornada de trabalho, saúde e segurança do trabalhador, remuneração, proteção ao trabalho feminino e infantojunvenil, dentre outros.

A exploração que favoreça o bem-estar dos empresários/empregadores e dos trabalhadores não é respeitada quando esses trabalhadores são submetidos a péssimas condições de labor, aviltantes da dignidade humana, e capazes de lhes causar prejuízos de ordem física, psíquica e social, como as que estão presentes em alguns casos de trabalho escravo, mormente na modalidade pautada em condições degradantes.

Importante destacar que o trabalho em condições análogas à de escravo afeta não somente o trabalhador a elas submetido, mas, também, a coletividade na medida em que 
propicia concorrência desleal em relação às empresas que respeitam a legislação trabalhista e, consequentemente, dispendem maior investimento nisso.

Sobre essa concorrência desleal e o desrespeito aos direitos básicos dos trabalhadores, Ferreira e Rodrigues destacam ainda a possibilidade da ocorrência do chamado Dumping Social Trabalhista que se traduz em uma prática empresarial desleal, com o intuito de eliminar a concorrência, através da venda de produtos a preço inferior ao de mercado. Para que tal preço seja praticado as empresas exploram seus trabalhadores, violando reiteradamente direitos trabalhista básicos. E acrescentam:

[...] o Dumping Social Trabalhista extrapola o limite da relação privada, prejudicando não só aqueles trabalhadores que têm os seus direitos reiteradamente violados, mas também o mercado econômico e as demais empresas com quem concorrem e que cumprem corretamente com a sua função social e respeitam os seus deveres trabalhistas e previdenciários. (FERREIRA e RODRIGUES, 2016, p. 281)

Assim sendo, a exploração excessiva do trabalhador, especialmente daquele submetido à condição análoga a de escravo, prejudica o seu convívio social, resultando em relações sociais desequilibradas; provoca o adoecimento deste trabalhador, que necessitará de assistência médica e previdenciária em demasia, dentre outras consequências negativas, também, à sociedade.

Com efeito, o trabalho escravo viola diversas garantias fundamentais, dentre elas, algumas das elencadas no art. $6^{\circ}$ da Constituição Federal, como a saúde, o trabalho (digno), o lazer, a previdência social e a proteção à maternidade e à infância, o que deteriora a relação jurídica de trabalho da maneira como foi concebida pelo ordenamento jurídico pátrio, especialmente no que tange à sua função social.

Enquanto modalidade contratual, a relação de trabalho deve garantir a coexistência do personalismo - figura característica dos contratos - com o respeito aos interesses da coletividade, o que se dá mediante o cumprimento da função social.

Em se tratando de contratos, o dever de não lesar condiciona o exercício do direito, o que, neste caso, significa que o cumprimento da função social, na forma da não exploração do trabalhador em condições análogas à de escravo, condicionará os direitos

Rev. de de Direitos Fundamentais Nas Relações Do Trabalho, Sociais E Empresariais | e-ISSN: 2525-9903 | Goiânia| v. 5 | n. 1 | p. 1-17| Jan/Jun. 2019 
de livre iniciativa, livre contratação entre as partes, poder diretivo patronal, dentre outros.

\section{CONCLUSÃO}

A relação de trabalho há muito deixou de ser vista como de interesse restrito às partes diretamente envolvidas, empregador e empregado, tornando-se de interesse, também, da coletividade. Isto se deve tanto por se tratar de relação manifestamente desigual, em que não há equilíbrio jurídico-econômico entre as partes, quanto porque dela emergem impactos na sociedade, direta ou indiretamente. Desta feita, passou-se a tratar o contrato de trabalho, também, ante seu caráter social, com restrições legais ao poder diretivo do empregador, como, por exemplo, a proteção das garantias fundamentais dos trabalhadores.

A realidade do Brasil, todavia, está longe de ser esta em que há garantia de proteção aos direitos fundamentais dos trabalhadores; isto porque diversas são as atividades econômicas que ignoram todo o regramento nacional e internacional e submetem seus trabalhadores a condições de trabalho similares às de escravos.

O trabalho análogo ao escravo pode ser compreendido como uma remodelação da escravidão colonial ou, mais precisamente, do plagium $^{l}$ da Roma Antiga, sendo que, na atualidade, o empregador se vale de sua posição hierarquicamente superior dentro da relação de trabalho para explorar o empregado além dos limites impostos por lei, seja por meio de trabalhos forçados, jornadas exaustivas, condições degradantes de labor e/ou servidão por dívidas.

Fatores como pobreza, vulnerabilidade socieconômica e desemprego contribuem para que alguns trabalhadores se vejam compelidos a aceitar quaisquer condições de trabalho, por mais aviltantes que sejam, a fim de garantir o sustento próprio e de sua família, todavia, não há

\footnotetext{
1 A este respeito, Brito Filho cita Pierangeli, o qual afirma que "A palavra plagium, etimologicamente, vem do verbo plagiare, que na Roma antiga significava a compra de um homem livre sabendo que o era, e retê-lo em servidão ou utilizá-lo como próprio servo" (PIERANGELI apud BRITO FILHO, 2017, p. 67)
} 
justificativa aceitável, jurídica ou moralmente, para a reiterada violação aos direitos humanos destes trabalhadores.

A natureza contratual da relação de trabalho pode, em um primeiro momento, e sustentada por uma concepção obsoleta e restritiva de que o contrato constitui lei entre as partes, indicar que elas poderiam convencionar irrestritamente seus termos, da maneira que melhor lhes servisse. Ocorre, contudo, que nesta relação não há igualdade entre as partes — jurídica, social, tampouco econômica —, o que faz com que um contrato de trabalho, que é, formalmente, bilateral, torne-se, na prática, mais próximo a um de adesão, em que, ao trabalhador, cabe somente aceitar os termos previamente estipulados pelo empregador, sem sobre eles possuir qualquer ingerência.

Desta feita, o contrato de trabalho possui limitações expressas tanto na CLT, lei específica que regula a relação laboral como um todo, quanto no Código Civil, dada sua natureza contratual, que atrai para si todo o arcabouço normativo atinente à teoria geral dos contratos.

Dentre estas limitações, está a função social dos contratos, que, no Direito Civil, restringe a liberdade das partes contratantes visando resguardar o interesse da coletividade que possa, eventualmente, ser afetado por aquele contrato.

O trabalho escravo, em quaisquer de seus modos de execução - expressamente previstos no art. 149 do Código Penal brasileiro — , viola a liberdade em sentido lato e a dignidade da pessoa humana, constituindo grave ofensa ao trabalho decente. Não podem e não são consideradas válidas juridicamente as práticas que exploram o trabalhador de modo a instrumentalizá-lo, tratando-o como se coisa fosse, ignorando aspectos de saúde e segurança no trabalho, e causando-lhe prejuízos de ordem biopsicossocial.

O contrato de trabalho, para cumprir sua função social, deve ser executado como instrumento de justiça e utilidade, e não apenas vislumbrando ganhos econômicos. Assim, a função social do contrato de trabalho está diretamente relacionada com a proteção da liberdade em sentido amplo e da dignidade do trabalhador, havendo, portanto, a obrigação de respeito aos mesmos, bem como aos demais direitos fundamentais dos trabalhadores.

Rev. de de Direitos Fundamentais Nas Relações Do Trabalho, Sociais E Empresariais | e-ISSN: 2525-9903 | Goiânia| v. 5 | n. 1 | p. 1-17| Jan/Jun. 2019 


\section{REFERÊNCIAS}

AZEVEDO NETO, Platon Teixeira de Azevedo. O trabalho decente como um direito humano. São Paulo: LTr, 2015.

BALES, Kevin; TRODD, Zoe; WILlIAMSON, Alex Kent. Modern slavery. London: Oneworld Publications, 2018.

BARBOSA, Leonardo Augusto de Andrade. Sobre a definição de trabalho escravo contemporâneo no Brasil: liberdade, dignidade e direitos fundamentais. In: PAIXÃO, Cristiano; CAVALCANTI, Tiago Muniz (org.). Combate ao trabalho escravo: conquistas, estratégias e desafios. São Paulo: LTr, 2017.

BRASIL. Constituição da República Federativa do Brasil. Disponível em: http://www.planalto.gov.br/ccivil_03/constituicao/constituicao.htm. Acesso em: 10 mar. 2019.

BRASIL. Decreto-Lei no 2.848, de 7 de novembro de 1940. Código Penal. Disponível em: http://www.planalto.gov.br/ccivil_03/decreto-lei/Del2848compilado.htm. Acesso em: 10 mar. 2019.

BRASIL. Decreto n. 41.721, de 25 de junho de 1957. Promulga as Convenções Internacionais do Trabalho de $\mathbf{n}^{0} 11,12,13,14,19,26,29,81,88,89,95,99,100$ e 101, firmadas pelo Brasil e outros países em sessões da Conferência Geral da Organização Internacional do Trabalho. Disponível em: http://www.planalto.gov.br/ccivil_03/decreto/Antigos/D41721.htm. Acesso em: 13 mar. 2019.

BRITO FILHO, José Claudio Monteiro de. Direitos humanos. São Paulo: LTr, 2015.

BRITO FILHO, José Claudio Monteiro de. Trabalho escravo: caracterização jurídica. 2. ed. São Paulo: LTr Editora, 2017.

BRITO FILHO, José Claudio Monteiro de. Trabalho decente: análise jurídica da exploração do trabalho - trabalho escravo e outras formas de trabalho indigno. 5. ed. atual. de acordo com a reforma trabalhista. São Paulo: LTr, 2018.

BRITO FILHO, José Claudio Monteiro de; ALBUQUERQUE, Ana Carolina Mendes de. Trabalho escravo na Amazônia. In: BASTOS, Elísio Augusto Velloso; FONSECA, Luciana Costa da; CICHOVSKI, Patrícia Blagitz. Direitos humanos na Amazônia. Salvador: Editora Juspodivm, 2017.

BRITO FILHO, José Claudio Monteiro de; MAUÉS, Elba Brito. O futuro do trabalho, o trabalho decente e a realidade das relações de trabalho no Brasil. In: PEREIRA, Emília de

Rev. de de Direitos Fundamentais Nas Relações Do Trabalho, Sociais E Empresariais | e-ISSN: 2525-9903 | Goiânia| v. 5 | n. 1 | p. 1-17| Jan/Jun. 2019 
Fátima da Silva Farinha; MENDES, Felipe Prata (org.). Direito do trabalho brasileiro: inovações e perspectivas. Rio de Janeira: Lúmen Juris, 2018.

CHAVES, Krystima Karem Oliveira; KOURY, Suzy Elizabeth Cavalcante. A efetividade da política de reinserção social do trabalhador resgatado da condição análoga à de escravo sob a perspectiva da teoria do desenvolvimento humano. In: REYMÃO, Ana Elizabeth Neirão e KOURY, Suzy Elizabeth Cavalcante. Desenvolvimento, trabalho e políticas públicas. Salvador: Editora Juspodivm, 2017.

CHAVES, Valena Jacob; HANNEMANN, Roberta Castro Alves de Paula. A jornada de trabalho dos caminhoneiros à luz do conceito de trabalho escravo contemporâneo no Brasil. In: REYMÃO, Ana Elizabeth Neirão e KOURY, Suzy Elizabeth Cavalcante. Desenvolvimento, trabalho e políticas públicas. Salvador: Editora Juspodivm, 2017.

FARIAS, Cristiano Chaves de; ROSENVALD, Nelson. Curso de direito civil: contratos teoria geral e contratos em espécie. 5. ed. São Paulo: Atlas, 2015.

FERREIRA, Vanessa Rocha. O dano existencial nas relações de trabalho e a eficácia horizontal dos direitos fundamentais nas relações privadas. RBSD - Revista Brasileira de Sociologia do Direito, v. 3, n. 1, p. 97-116, jan./abr. 2016.

FERREIRA, Vanessa Rocha. Trabalho forçado: a escravidão contemporânea e a violação da dignidade humana. In: Direitos Humanos na contemporaneidade. Curitiba: Juruá Editora. 2017. p. 163-196.

FERREIRA, Vanessa Rocha; RODRIGUES, Leonardo Nascimento. Dumping social trabalhista: caracterização e aspectos polêmicos. In: Dumping social no Direito do Trabalho e no Direito Econômico. Curitiba: Editora Juruá, 2016. p. 275-292.

KANT, Immanuel. Fundamentação da metafísica dos costumes. Tradução de Paulo Quintela. Lisboa. Portugal: Edições 70, 2003.

MARANHÃO, Ney. Poluição labor-ambiental: Abordagem conceitual da degradação das condições de trabalho, da organização do trabalho e das relações interpessoais travadas no contexto laborativo. Rio de Janeiro: Lumen Juris, 2017.

MARTINEZ, Luciano. Curso de direito do trabalho: relações individuais, sindicais e coletivas de trabalho. 9. ed. São Paulo: Saraiva Educação, 2018.

MARTINS, Sergio Pinto. Direito do trabalho. 27. ed. São Paulo: Atlas, 2011.

MESQUITA, Valena Jacob Chaves. O trabalho análogo ao de escravo: uma análise jurisprudencial do crime no TRF da 1ª região. Belo Horizonte: RTM, 2016.

Rev. de de Direitos Fundamentais Nas Relações Do Trabalho, Sociais E Empresariais | e-ISSN: 2525-9903 | Goiânia | v. 5 | n. 1 | p. 1-17| Jan/Jun. 2019 
NEVES, Débora Maria Ribeiro. Trabalho escravo e aliciamento. São Paulo: LTr, 2012.

SANDEL, Michael. Justiça: o que é fazer a coisa certa. 4 ed. Rio de Janeiro: Civilização Brasileira, 2011.

SANTOS, José Aparecido dos. Função social do contrato nas relações de trabalho e de consumo. In: Anais do XVI Congresso Nacional do CONPEDI - Conselho Nacional de Pesquisa e Pós-graduação em Direito. Florianópolis: Fundação Boiteux, 2007. p. 4765-4785.

SEDWICK, Sally. Fundamentação da metafísica dos costumes: uma chave de leitura. Petrópolis: Editora Vozes Ltda., 2017

VELLOSO, Gabriel; FAVA, Marcos Neves. Trabalho escravo contemporâneo: o desafio de superar a negação. São Paulo: LTr, 2006. 